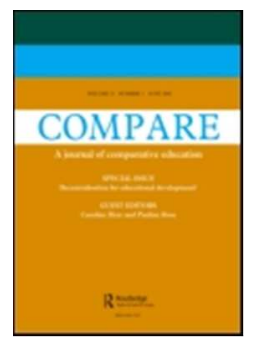

\title{
Exploring collaborative interaction and self-direction in Teacher Learning Teams: case-studies from a middle- income country analysed using Vygotskian theory
}

\begin{tabular}{|r|l|}
\hline Journal: & Compare: A Journal of Comparative and International Education \\
\hline Manuscript ID & CCOM-2018-0025.R2 \\
\hline Manuscript Type: & Original Article \\
\hline Keywords: & $\begin{array}{l}\text { Collaborative interaction, Self-direction, Egyptian system, Teacher Learning } \\
\text { Teams, Vygotsky's theories of learning and development }\end{array}$ \\
\hline Abstract: & $\begin{array}{l}\text { This article explores teachers' learning from a Vygotskian perspective } \\
\text { which emphasises collaborative interaction and self-direction. The article } \\
\text { describes case-studies of three Senior Teachers in socio-economically } \\
\text { disadvantaged Egyptian primary schools where collaboration and self- } \\
\text { direction were systemically discouraged. It analyses how, through a } \\
\text { teacher development Intervention, the teachers learned to use } \\
\text { collaborative interaction to support their own learning and felt more } \\
\text { creative, authoritative and powerful after being guided to exercise self- } \\
\text { direction. }\end{array}$ \\
\hline
\end{tabular}




\title{
Exploring collaborative interaction and self-direction in Teacher Learning Teams: case- studies from a middle-income country analysed using Vygotskian theory \\ Dr. Eleanore Hargreaves, UCL Institute of Education, 20 Bedford Way, London WC1H OAL Dr. Dalia ElHawary, Department for Curriculum and Instruction, Alexandria University, Egypt.
}

\begin{abstract}
This article explores teachers' learning from a Vygotskian perspective which emphasises collaborative interaction and self-direction. The article describes case-studies of three Senior Teachers in socio-economically disadvantaged Egyptian primary schools where collaboration and self-direction were systemically discouraged. It analyses how, through a teacher development Intervention, the teachers learned to use collaborative interaction to support their own learning and felt more creative, authoritative and powerful after being guided to exercise self-direction.
\end{abstract}

\section{BACKGROUND AND THEORETICAL FRAMEWORK}

Extensive literature on sustainable professional development has indicated that participating teachers must have capacity for both collaborative interaction and selfdirection (Leahy and Wiliam 2011). This article re-explores these aspects of learning in the Egyptian context where, as in many middle and low-income countries from Nigeria to Jamaica to Myanmar, neither collaborative interaction nor self-direction have systemic support (Hammad 2010). The article offers a novel approach to exploring teacher development, through a Vygotskian lens. Vygotsky's $(1986 ; 1978)$ theories about how people learn were originally applied to pupils' learning rather than teachers' (e.g. Yandell 2007). In the case of pupils, the target is the development of academic (or scientific) concepts. However, for adult teachers, learning and pedagogy become the focus instead. As 
our professional development Intervention proceeded, Vygotsky's theories proved to be significant. 


\section{Academic significance of the article}

This article provides case-studies of the professional learning and development of three Senior Teachers in socio-economically disadvantaged Egyptian primary schools who took part in the TLT-Intervention. It investigates their own views of learning and development. It explores how they described collaborative interaction and self-direction influencing their professional learning across the eight-month Intervention. By professional learning, we borrow Rogers' (1951) definition of change as in 'the organisation of self' (390): that is, of a shift in how they perceived and enacted their own learning and their support for others' learning. Where their change seemed significant and irreversible, we refer to their learning as transformative, in Mesirow's (1990) sense:

Becoming critically aware of how and why our presuppositions have come to constrain the way we perceive, understand and feel about our world (14).

Transformative learning involved re-defining themselves, in relation to others, thereby potentially moving beyond localised learning to long-term development.

The relevance of this research lies in its task of more fully understanding the complex interplay between individual teachers' professional development and Vygotsky's emphasis on collaborative interaction and self-direction. The findings will be particularly relevant to the many countries of the world where teachers' collaborative and self-directed learning are dismissed in favour of conformity to those with more powerful hierarchical positions. Some authors suggest that such a hierarchical approach has prevailed in Egypt (and other countries in the global south) partly because beliefs there about the individual's role in society are 'diametrically opposed to Western or at least mainstream US assumptions' (Atkinson 1977, 80, cited in Ab Kadir 2017, 242). Hammad $(2010,108)$ described how 
Egyptian teachers' fears of 'chaos' and 'conflict' seemed 'to be rooted in a greater societal emphasis on social cohesion and harmony'. Pratt (2007) proposed that, for ex-colonial countries such as Egypt, this was a result of previous subjugation. Thereby, there has seemed to linger 'a deeply entrenched culture of obedience and conformity... that compels the rights and privileges of the larger society over the individual' (Ab Kadir 2017, 237). These assumptions tend to be in tension with constructivist models of teachers' learning, where teachers' creativity and diversity may be more highly valued than conformity to existing structures.

\section{Professional development Intervention using Teacher Learning Teams [TLTs]}

The processes which we call here the "Intervention" included the introduction into six Egyptian primary schools the system of Teacher Learning Communities [TLCs] or "Teacher Learning Teams" as they were re-named in Egypt (hence "TLTs"). We adapted Leahy and Wiliam's (2011) design for TLCs but replaced their focus on formative assessment with learning and teaching English as a foreign language. After spending time in Egyptian primary classrooms (see Hargreaves, Mahgoub and Elhawary 2016), as a team of researchers, we perceived that some essential ingredients for professional learning were missing from teachers' experiences: specifically, opportunities for collaborative interaction; and for directing learning according to individual need and interest. Recent reviews of teacher professional development suggest that TLCs (or TLTs) embody characteristics closely associated with sustained improvements in teachers' development (Belibas, Bulut and Gedik 2017; Earley and Porritt 2010; Leahy and Wiliam 2011; Philpott and Oates 2017; Stoll et al. 2006; Tannehill and MacPhail 2017). This improvement is attributed to the fact that TLCs are founded on teachers identifying their own focus for, and process of, professional development. In this model, teachers are expected to collaborate with each other in order 
to learn; input from beyond the school is also helpful, although the main site for development is the school. None of these foundational aspects characterised teachers' planned learning in Egyptian schools (see also Hammad 2010).

\section{Vygotsky's theories about collaborative interaction}

Collaborative interaction among teachers has been frequently described as a key feature of successful professional development (Bellibas et al. 2017; King 2014; Tannehill and MacPhail 2017) and is central to the structure of TLTs [TLCs]. In Vygotskian terms specifically, the term 'collaborative interaction' refers to any situation in which the learner is being offered interaction with another person or people. This person or people provide support for a problem that the learner wants to solve: '... through demonstration, leading questions, and by introducing elements of the task's solution' (Vygotsky [1987, 209] in Chaiklin [2003, 54]). How much each teacher could benefit would depend on their existing levels of perception, thought and will. As Chaiklin $(2003,49)$ suggested, existing levels would reflect 'institutionalized demands and expectations that developed historically in a particular societal tradition of practice'.

\section{Vygotsky's theories about self-direction}

Reviews of teacher development through TLCs (e.g. Philpott and Oates 2017; Tannehill and MacPhail 2017) indicate that effective teacher professional development depends on teachers exercising proactive self-direction; in particular, it is effective when a learning need is identified as important by participants themselves and action taken and supported accordingly. This is an often-overlooked aspect of teacher professional development, particularly in countries like Egypt where theoretical, university-based training still has the dominant place in the hierarchy of valued knowledge (see Hammad 2016). The organisation 
of TLTs, in contrast, focused explicitly on strategies identified by teachers themselves as useful for their own classrooms.

Vygotsky emphasised that volition and interest led the developmental process. Chaiklin $(2003,47)$ described how, from a Vygotskian view, learners noticed their current capabilities and compared these to their 'needs and desires, and the demands and possibilities of the environment'. In trying to overcome this gap between current and desired capabilities, and to realize particular action, the learner willingly engaged in tasks and interactions which allowed 'the formation of new functions or the enrichment of existing functions' $(2003,47)$. Teachers thereby perceived themselves more as subjects than as objects of development (Philpott and Oates 2017).

As Vygotsky stressed, self-direction may begin during collaborative interaction: through speaking with others, any simple action was raised to a higher level and subjected to the power of the learner who 'puts upon the action the stamp of will'. It was this stamping, during interaction, that made the learner's action 'free' (Vygotsky 1933, in van der Veer \& Valsiner 1991, 345). In other words, reflection by the individual could be spawned from collaborative interaction (Shayer 2003, 481) which led to freely adopted action. Rewards, punishments or persuasion would not substitute the teacher's own volition and interest (Niemiec and Ryan 2009). Self-direction therefore suggests creating, or controlling for oneself, a situation, by taking an informed initiative, rather than waiting for things to be done for or to oneself. Important tools that support the taking of initiative are collaborative interaction with peers; as well as the teacher's own observation of how their actions are making change which 'can give teachers an authoritative basis for their views' (Philpott and Oates 2017, 327). However, as Philpott and Oates (2017) point out, in a tightly controlled 
system, such as the Egyptian system, these 'alternative discourses' may have to be learnt from beyond the school (327).

\section{Application to the research}

In the TLT-Intervention on which this research was based, the researchers led the Intervention (while at the same time carrying out the research on the Intervention) as 'More Capable Instructors'. They aimed to awaken 'a variety of internal developmental processes' in each Senior Teacher through collaborative interaction during meetings (Vygotsky [1978, $90]$ cited in Shayer $[2003,471])$. Collaborative interaction implied the valuing of each teacher's insights and contributions to others' learning. In our TLT-Intervention, this unselfish respect for others' aspirations, without thought of personal gratification, was a particular challenge for Senior Teachers, in a context where participants often faced fierce competitiveness among colleagues who were used to being oppressed by those with power over them (see also Hammad 2010). Our research therefore explored whether teachers could learn and develop professionally despite these tensions, benefiting from collaborative interaction as well as self-direction.

\section{RESEARCH DESIGN}

The following sections describe the principles according to which this research was conducted. It used an interpretivist approach. Without denying the existence of one 'reality' underlying people's interpretations, we were interested in exploring how this reality was constructed by seven Senior Teachers in Alexandrian primary schools and how we could make sense of these constructions (Guba and Lincoln 1985; Maxwell 2012).

\section{Sample}


Our research sample of Senior Teachers consisted of all the teachers signed up for the TLTIntervention: four female teachers from three National Institute schools, which were government schools with some private funding. We also worked with three male teachers at AlAzhar schools which were government-controlled with support from AlAzhar university and mosque in Cairo. All participating schools were relatively disadvantaged socioeconomically, but the AlAzhar schools took some of Egypt's poorest children. The Senior Teachers involved were those who had been teaching for an extended period, who monitored the learning and teaching of less experienced teachers.

Context of the research: the Intervention

Funded and directed by the Education Development Trust, we as consultants led the Intervention as a team of Egyptian and English educators (two of whom are authors of this article, one Egyptian, one English). The TLT-Intervention aimed to support the learning and teaching of English. We academic researchers, however, also used the TLT-Intervention as a means to investigate teachers' professional use of collaborative interaction and selfdirection.

As described also by Hammad (2010), there tended to be a lack of trust among Egyptian teachers, as well as a lack of experience, in making professional decisions. Therefore the following three initial training sessions for the Senior Teachers were considered essential for the success of the TLT-Intervention and took place towards the end of 2015:

1) Two days on leadership generally, to explore alternatives to the dominant autocratic model;

2) Two days on "Coaching" specifically (Carnell, MacDonald \& Askew 2006). This was a leadership approach which entailed empathetic listening to others rather than the giving of 
instructions or making demands (as in the normal image of "leadership"). This approach demanded a more equal relationship between leader and led and assumed more selfdirection on the part of the led; and

3) Two days on leading TLTs as communities in which the Senior Teacher and her/his Team of teachers shared/developed practices and reflections.

From each school, one Senior Teacher attended initial training sessions.

In February 2016, we then hosted a workshop to which Senior Teachers brought all their TLT teachers to share and demonstrate their new ideas with others: this turned out to be an extremely unusual but highly appreciated occurrence in their context (see also Hammad 2016). In March, the seven Senior Teachers made a presentation at an international conference in Jordan: this was also a rare and valuable opportunity that was normally left only to those in higher hierarchical positions.

Apart from these discrete training sessions, the seven Senior Teachers met together every month to discuss and reflect on how their professional development was progressing; and how their support to other [TLT] teachers' professional development was flourishing under their guidance. Each Senior Teacher had been initially observed by one consultant as they carried out an innovative five-minute 'action' in their classroom which was integrated to support their tightly-prescribed syllabus. The action was planned on an Action Plan to meet self-identified goals. Goals included, for example, improving speaking, focusing on struggling pupils, making learning more active.

TLTs had been set up in each school by the Senior Teacher. In mid-November, each Senior Teacher had led their first TLT meeting, supported by consultants. After this TLT meeting, the TLT teachers had also tried out their own innovative five-minute actions in their English 
classrooms. Teachers observed each other during these actions. In each subsequent TLT meeting, the Senior Teacher invited the group to:

- Describe, then analyse as a team, what happened when they tried out the planned five-minute action in their classroom.

- Decide on a revised Action Plan for the forthcoming month and decide which colleague would observe it.

As consultants, we provided ongoing input to support Senior Teachers' coaching skills; and attended TLT meetings and observed classrooms if invited.

Data collection during the Intervention

In this article, we present the cases of only three Senior Teachers who led TLTs, drawing exclusively on interview data. We refer informally also to our attendance at their TLT meetings in their schools. We chose to use our available space here to focus in detail on three participants rather than to collate our findings across all seven, because the development journey itself, and each Senior Teacher's specific environment, were important for understanding how they used collaborative interaction and self-direction. The decision also reflects our belief that each teacher's journey across the year was original and whole in itself (Fielding 1996) and needed to be narrated holistically. Findings relating to all seven Senior Teachers can be found elsewhere (Hargreaves and ElHawary 2018).

The three Senior Teachers we selected did, however, represent all seven as much as possible. For example, they included two women and one man of different ages, who came from three very different schools and who responded diversely to the TLT-Intervention activities. They were (using pseudonyms): Laila, Saif and Farida. We carried out three indepth interviews in November, January and May, 2015-16, with each Senior Teacher plus an 
additional one with Saif in September 2015. All interviews were transcribed and translated from Arabic by the dedicated Intervention translator, in constant dialogue with one author of this paper (who is herself bilingual).

\section{Data analysis}

There were several stages to our data analysis, which the two main researchers carried out collaboratively. As interviews were transcribed, we studied the transcriptions and prepared our next interview schedule accordingly [September, November, January, May]. By May, we were very familiar with the data. Basing our strategy on Grounded Theory (Glaser and Strauss, 1967), we then looked inductively for themes raised in all the interviews. Our focus had always been collaborative interaction and self-direction, but we noticed a range of unanticipated aspects to these as they developed across the Intervention. Other themes emerged in interviews too. We therefore drew aside those instances where collaborative interaction and self-direction were clearly addressed and re-examined these texts for subthemes. We found that often these sub-themes linked directly to our understanding of Vygotsky's theories about learning. For example, our sub-themes included:

- Appreciation/encouragement;

- Enjoyment, curiosity, innovation, creativity;

- Confidence in self/gaining a sense of authority;

- Teamwork/listening to others;

- Consultants' demonstration.

We therefore re-analysed the dataset, with these sub-themes in mind. This time, we looked specifically for how each of our participants talked about the sub-themes we had developed. During this process we selected those three leaders whose journeys we 
believed would best represent the whole group's professional development across the TLTIntervention. [After each citation below, the month of interview is noted to highlight chronological progression e.g. 'JanInt' denotes an interview carried out in January].

\section{Ethical issues}

This research, both in its design and fieldwork, adhered to the BSA ethical guidelines (2002). We explained to Senior Teachers that the purposes of our research were to explore means for developing English teaching. It appeared that they were not worried about the specific details of the research but most interested in working with academics from outside their schools who could give them support for English teaching. They had ample opportunities to withdraw from the research which ran from September 2015 to May 2016; but they were all keen to take part and signed their consent willingly. Their identities have been disguised so that only the participants themselves could detect their real roles.

\section{FINDINGS}

\section{Laila}

Laila was a mature teacher of Year 6 pupils in an English language school. Laila was an interesting case because, when she started the TLT-Intervention, she seemed professional and well-organised in terms of her own learning, teaching and leadership. However, during the TLT-Intervention, she noticed significant progress in all three. The goal of Laila's own five-minute activities for pupils was to improve the learning of her lowest-attaining pupils. She therefore experimented with differentiation by giving pupils a choice of task, without deciding for her pupils who should choose which level of task. This was extremely innovative in her context.

\section{Laila's learning through and about collaborative interaction}


Laila's description of her collaborative interactions at the start of the TLT-Intervention suggested that, unusually, she already had interactive relationships with her teachers and pupils and considered their contributions as sources for her own learning. As Senior Teacher, she consulted even her youngest teachers and gave them choices. She also valued collaborative interaction with pupils, parents and the wider community, including those outside the system:

I like the new and crazy ideas from the younger generation... I like to take feedback from parents by asking our relatives, friends, neighbours; and getting their feedback. They are distant from the process itself so their feedback can be very helpful [Novint].

During the TLT-Intervention, Laila felt that she gained by conversing with teachers from the different Intervention schools because she noticed that everyone had similar problems and this made her feel 'normal'. However, in November, she told us that teachers from her school could not learn from the teachers in the AIAzhar schools because English there was of a lower level. However, after interaction with these teachers at the February workshop, Laila's view shifted:

[My teachers] were very affected by the [AlAzhar] groups. They saw in the videos how basic their facilities were and how weak their students were and they still managed to do something! This really motivated them [Maylnt].

Laila also changed how she collaborated with her teachers. Unlike any of the other Senior Teachers, prior to the TLT-Intervention she already gathered together her teachers in a weekly meeting where they discussed more than just the syllabus. In November, she described those existing meetings as very useful because in them she was able to find out 
'what people are thinking and feeling' [NovInt]. In these meetings, she had always treated her teachers as colleagues, reflecting her developmental rather than hierarchical perspective. However, she perceived the situation as follows: 'They sit with me and I make things easier for them by telling them what to do' [Novlnt]. By May, she displayed a difference: now, she emphasised that she learnt more from her teachers than they gained from her. In particular, they gave her encouragement. She suggested that the learning by each person, including herself, exceeded that which could have been attained by each individual in isolation. She explained:

As a leader, I learnt how I can help the people around me and how they can help me. Actually, they might have helped me more than I helped them... I felt we were really helping each other. If that could occur more often, what would happen? We were four, and we all benefited. If that had been applied more widely - imagine the effect!

Laila also described the common phenomenon in the Egyptian context, that many teachers did not know how to collaborate and sometimes chose to work alone because it was easier. As she came to see how others enhanced her own learning, she had changed the mentality among her own teachers and was now hoping to prepare the pupils in their classes for a more collaborative outlook that they could take with them into adulthood.

\section{Laila's learning through and about self-direction}

Laila illustrated self-direction as 'new spirit' whereby, because of the TLT meetings, she and her teachers came to see a clear development goal and feel inspired to reach that goal [Maylnt]. The 'new spirit' often included enjoyment and curiosity; and was closely allied to innovation and creativity. In Laila's view: 
Anything that doesn't change will fail. If you don't develop it, it will die. You must innovate in everything or it won't have spirit ... Over time, teaching the same thing, you get bored of what you are doing. It becomes simply a routine... I used to use the same activities each time. I was not creating anything. I started after the TLTIntervention to think of other things [Maylnt].

She described how innovation might increase exponentially, moving teachers from choosing just how to teach to deciding how and what to teach. This illustrated Vygotsky's idea of gradual independence from a More Capable Instructor. In addition, and in contrast with local tradition, Laila felt that older teachers needed to capture the spirit of self-directed experimentation from their younger colleagues:

Those who have been teaching for 10 to 15 years are stuck and need to go to courses and need to widen their horizons. They need to get out of their staffrooms and meet new people and discover new ideas [Maylnt].

However, she was clear that, to ignite this spirit, the school's administration needed to give teachers the chance to choose which programmes they wanted to attend rather than imposing training programmes on them. The fact that the current TLT-Intervention had been voluntary was a vital part of its benefit. Laila seemed to suggest that the spirit of innovation ignited a determination to improve; and as improvements occurred, confidence increased which bred further spirit and stronger determination.

For herself, she found the experience at the conference in Jordan encouraging especially after Senior Teachers 'stood up and did our own things' [Maylnt]. Then she started to feel that she could do workshops for other teachers herself, because of a new sense of her own authority. In any workshops that she proposed to give, she said that she would use the 
model demonstrated by the TLT-Intervention: allowing participants to identify their own needs; making sure that they were engaged and enjoying the workshop. She was building on her own growing awareness of the need for choice, participation and enjoyment in development:

First, I will give them the choices for what topic I will talk about. Then think about the steps of the presentation. And prepare handouts so the presentation isn't boring. And think about how to get them to participate [Maylnt].

She claimed that choice, enjoyment and participation were essential to her TLT teachers' learning too, and they experienced these when doing peer observations. Laila came to see that the unannounced lesson observations that she used to conduct as Senior Teacher were neither useful nor fair. Now she perceived that each teacher should choose who observed them, and also which lesson, if they were actually going to learn from the experience.

Laila explicitly expressed how, during the TLT-Intervention, she and her teachers gradually progressed towards a new level of conceptualisation in relation to professional practice. This included formation of new functions and enrichment of existing functions. As she summarised it: 'When [people] work in pairs and groups, they get lots of ideas. Or, the ideas were already there, but they needed to bring them out' [Maylnt]. She saw how through processes of collaborative interaction and self-direction, she could overcome gaps between her current and her desired capabilities. For example, when she became Senior Teacher, she found herself responsible for a whole department but had not received professional training to grasp her new responsibilities. Supervisors visited from the Ministry of Education but came 'just to do paperwork'. It was the TLT-Intervention which helped to clarify for her how to be a better leader of teachers by supporting her to use certain tools. This was a 
classic example of how guidance from a More Capable Instructor [in this case, the Intervention consultants] allowed her to achieve more with their support than she would have done alone, as she crossed through her Zone of Proximal Development (Vygotsky 1978). In another example, in relation to coaching, she noticed that she was already doing coaching when the TLT-Intervention began. But she reflected:

I wasn't very aware of the way to do it. I was doing it randomly. But you made it more comprehensive and organised. You organised my ideas [Maylnt].

\section{Summary of Laila's Case}

In Laila's case, learning meant nurturing 'spirit' which was ignited by collaborative interaction, choice, enjoyment and participation, which led to an unfolding sense of selfdirection and awareness of her own authority. The guidance she received from the consultants took the form of demonstration and clarification of concepts and practices that had been vague in her consciousness. Consultants and other teachers also provided encouragement and stimulus for her learning and development.

\section{Saif}

Saif was a male teacher in his thirties who taught middle school girls in one of AlAzhar's Islamic schools; and was Senior Teacher in their primary school too. He was an enthusiastic member of the TLT-Intervention's cross-school Senior Teachers' group and never missed sessions. The goal of the five-minute activities that he developed for his pupils was to improve his pupils' interaction in English. The activity consisted of pupils writing their own short play-scripts and performing them in class. This activity seemed to revitalise his classes 
and his own learning significantly. However, Saif's TLT appeared somewhat fragmented and keeping it coherent became a struggle.

\section{Saif's learning through and about collaborative interaction}

Saif described having 'spiritual aims and motivation' [Janlnt] and explained that the Qur'an itself eulogised education as a means for improving people's lives. One reason for caring particularly about English teaching was so that his students could 'explain Islam and Islamic civilisation to others' [Maylnt]. He also believed that Egyptians could learn from Englishspeaking countries and people. Saif talked extensively about connecting with other people to 'exchange experience' [Janlnt]. He described how at school, before the TLT-Intervention, he was not asked to express his opinions, there were no discussions and, most importantly, no shared educational goals towards which to strive. Yet, he himself seemed to learn from a wide range of others in his environment, despite this lack of systemic encouragement. Saif described how other teachers in his TLT, and also of different subjects in his school, helped him think about changing his teaching. Over the course of the TLT-Intervention, he came to realise that students too had a lot to offer him for improving the way he taught.

The Intervention consultants' apparent confidence in him and exchange of ideas with him also helped him change. His exposure to other English speakers from a range of countries during the conference in Jordan, also motivated him as he perceived himself to belong to a wider community of English speakers. In contrast, not many teachers felt valued in Egypt, according to Saif, and they therefore lacked confidence and also lacked the will to develop. He described the teacher as being 'the lowest person in the state... perhaps less than the rubbish collector' [Janlnt]. However, Saif suggested that his increased sense of professional authority was due to the TLT-Intervention and due to the educational research that 
underpinned it. He believed that the 'academic' input of the TLT-Intervention, based on research, gave the TLT-Intervention power, because teachers had learnt 'something real' [Janlnt].

Saif recounted that the TLT-Intervention allowed him and his teachers to benefit from teamwork and so progress towards development. Already in September, Saif himself advocated an egalitarian view of teamwork as essential for learning. Whilst he recognised his approach as unusual for his culture, his insight was that an open exchange of ideas had to happen in order for learning to flourish:

We can work together and see the strengths and weaknesses among us and try to fix them... I might suggest a way of teaching as an idea: not as an order. We might do brainstorming: I say my ideas, the teachers say their ideas. We consider what emerges from it; and what will be in the best interests of the students [Seplnt].

This unusual openness to others' views even extended later into his classroom, despite the hierarchical traditions of his teaching-learning environment. He mentioned several times that he aimed to nurture a family-like culture in his classrooms where pupils and the teacher learnt from each other on a continuous basis.

Saif recognised the role of demonstration in the consultants' support for his own learning as part of a different 'family': the group of the Senior Teachers from the six different schools. It is fascinating that he attributed the 'family approach' to the consultants' greater experience:

The family spirit - we [Senior Teachers] felt like a family. This encouraged us a lot. There wasn't a sense that anyone was inferior... I learnt it from you and your academic background. You supported us like your younger siblings. So, we were able 
to apply this in practice, not just in theory... What we do with you [consultants], we do with our teachers, and the teachers do with the students. It's a chain [Maylnt].

\section{Saif's learning through and about self-direction}

Saif was already very aware that learning should start where the learner was positioned socially and psychologically. He saw clearly that when learners perceived their learning as 'personally meaningful' (Rogers 1951, 427) they made the effort to progress. Saif could obviously see Vygotsky's point that learning must be subjected to the will of the learner. He saw that coercion blocked development:

The best thing [about the TLT-Intervention] was that you didn't force anyone to participate. If I was forced to join, I wouldn't participate well. When you feel you are there by choice, this makes you want to try. We felt we could go and try, and we didn't have to continue if we didn't like it. So we had nothing to lose. There were no penalties for not joining... When you are forced to attend, you just sit there, and you won't apply what you hear [Maylnt].

Saif noted that when his TLT teachers wanted to learn and then got the support from him as Senior Teacher, then it would happen: so long as he gave his support willingly without hope of personal gratification. Saif told us about the success of peer observations in which each teacher chose who would observe them, as they practised a new teaching activity, and looked only at the points requested by the practising teacher. These helped teachers to think of ways to improve their practice. This contrasted with past observations, whereby supervisors had deliberately looked for weak points in order to assert their superiority, thereby tending to block development. 
However, in order to develop their teaching approaches fruitfully, Saif reminded us that he and his teachers needed more time, more space, more support from the school administration and, most importantly for Saif, they needed to remain in one school for a predictable length of time to build up collaborative relationships. Saif suggested that five years would be an appropriate amount of time for genuine change to happen. Significant change could not occur in his own situation where he was working in two schools at once and could be transferred to another at any time. During one TLT in Saif's school, we saw a young teacher being taken away from the TLT to attend a different training session, against her will and against Saif's will. This disrupted the group's collaborations and reminded Saif of the systemic limitations to self-direction.

In relation to the importance of the learner's own will as the driver of learning, Saif mentioned on numerous occasions how sharing a specific goal inspired his own and his teachers' drive to learn. Choosing and clarifying a goal collaboratively seemed to open him up to richer interactions in order to achieve his goal. One way to support the achievement of this agreed goal was by teachers asking each other questions:

The most useful thing [in the TLT] was that everyone could ask their questions and get answers. If someone, for example, had a problem controlling their class, everyone would suggest an idea. We would get new and real-life ideas. We weren't working alone. We had set steps to follow. We were focused on one point [Maylnt]. In order to learn, Saif worked with the demands and possibilities of all aspects of his environment and tried to make best use of these. He talked about proactively researching 'new developments' in pedagogy, online. He also constantly asked us whether we as consultants could provide him with more English language and pedagogical training. We did 
note that Saif sustained some deference to foreigners' authority which he perhaps associated with the authors of the educational research he valued. While approval from any person in a high position was greatly valued in Saif's system, approval from 'native' English speakers was especially desirable for Saif. Saif explained that his pupils waited eagerly for our visits to their school because of the opportunity of being seen by fluent English speakers. On each visit by consultants to his school, many photos and videos were taken and courtesies exchanged, sometimes to the point of obstructing formal learning. At first we tried to avoid being given this special treatment, but on reflection we wondered whether it was actually one aspect of Saif working with the demands and possibilities of his environment and making best use of these. Saif was quick to point out that he would not necessarily import foreigners' ideas wholesale into their system. He added, 'We might change them to suit our circumstances and materials'. However, it was clear that collaborative interaction with fluent English speakers was an important means towards his developmental goals. And it was also a satisfaction of that goal itself.

\section{Summary of Saif's Case}

In summary, Saif expressed a view of learning as leading to a higher development of himself as a person, in terms of his authority, knowledge, ways of supporting others and as part of an English-speaking community. While he was already a collaborative professional when the TLT-Intervention started, he told us that he had learnt to value collaborative interaction further during the Intervention as he saw how it supported him to engage with and listen to a range of insightful views. He also began to believe in the power of his own self-directive capacities as he gradually perceived their effects. Despite many systemic obstacles to his collaboration and self-direction, Saif became extremely driven during the TLT-Intervention 
to achieve his ambitious, but strategic, goals of becoming an authoritative, supportive leader and teacher with a good command of the English language; and he pursued all the means to learning that he could access.

\section{Farida}

Farida was a female teacher in her thirties who taught Year 6 in a small National Institute school which prioritised English. She had two teachers in her TLT who seemed committed to Farida's leadership and to the TLT, although unfortunately one of them was on sick-leave for some time during the TLT-Intervention. Farida had a low profile initially but nearer the end of the TLT-Intervention, she seemed suddenly to perceive learning and teaching differently and take a more active role. The five-minute activities she developed focused on the goal of improving writing in English. She experimented in using groupwork in class for creative writing. A turning point for her was when she realised that pupils did not need to copy lists from the black-board and that collaborative groupwork was a better use of time.

\section{Farida's learning through and about collaborative interaction}

Farida was clear that for her pupils, learning was more than passing exams but she felt pressured by parents who did not share her vision. She believed that learning English included interacting in English as well as developing personal skills such as decision-making and supporting peers. Her own most valued learning and development goal was to act as a motivational source to others:

\footnotetext{
The [Senior Teacher] sets the atmosphere from the beginning. If they don't do this, there won't be any collaborative interaction. We have to set the atmosphere and try to collaborate. This will result in new ideas and development [Maylnt].
} 
One of Farida's most significant learnings was discovering that discussion of ideas was developmental: for herself in Senior Teacher meetings; for her teachers in TLT meetings; and for pupils in lessons that incorporated groupwork:

I wasn't convinced by peer learning. I didn't understand how it could work. But it really worked. Sometimes they were able to explain to each other better than I was... How do they learn from each other? I didn't know they could learn from each other! [Maylnt].

Farida was emphatic about how supportive to her own learning the cross-school Senior Teacher meetings were. She had never sat with teachers from other schools more than in a one-day training event. She came to realise that they all had similar difficulties but that it was possible to negotiate ways of dealing with these. She became very motivated when she saw how driven and enthusiastic teachers from the AlAzhar schools were, which she described as 'those who have the least facilities in the world' [Janlnt]. She began to acknowledge to herself that her school was more privileged than theirs and that she actually had more support than they did, thereby redefining how she perceived her own position; and also giving her hope. In fact she started to see that her teachers were also doing valuable activities like the teachers in other schools.

This learning boosted Farida's self-confidence and her confidence in her teachers. She told us that this seemed to affect teachers of other subjects in her school too, who were 'curious about what we were doing'. She also felt connected to a much wider, highly respected community of English teachers, after making the presentation at the international conference in Jordan. As she expressed it: 'All of this added to me' [Maylnt]. In other words, these factors changed how she viewed herself professionally in relation to others. 
One aspect of learning that was important for Farida was observing the impact of her actions among her teachers and pupils. This was the basis for her increasing confidence and sense of authority which led, in turn, to further action. She perceived that this was because she was 'solving real problems'. In terms of how Farida perceived support to be provided for her own learning, she saw a significant role for 'experts' outside school. She appreciated the consultants' visits very highly but wanted more of these and more direction from consultants. Even at the end of the TLT-Intervention, she continued to ask consultants to provide ready-made pupil activities, even though at other times she recognised the importance of self-direction in her own learning, as described below.

An important aspect of her learning was having a specific, shared goal and feeling that she could reach it, with support. When she first started leading TLTs, she thought there would be little to talk about but then: '... Found we talked about many important things' [Maylnt]. What made discussion powerful for learning, she claimed, was that it was a very focused discussion with each person working towards the same goal. This contrasted with the fragmented system she experienced beforehand [Janlnt].

Farida described perceiving her teachers in a different, less critical way than before:

After I went to Gamila's class and saw her classes and how the students reacted to her, I respected her a lot more. Why had I limited her role and not realised how good she was? ... She also had new ideas ... She developed the ideas. I don't have these ideas! My view of my teachers changed [Maylnt].

Farida also mentioned the important role of appreciation. Her TLT teachers were motivated by the fact that, when presenting their work among colleagues at the February workshop, Farida encouraged her TLT teachers by mentioning all their various achievements. This was 
something that she reported her own school's administration did not do well but which could have encouraged her own development.

\section{Farida's learning through and about self-direction}

It was noticeable that Farida lacked confidence in herself at the start of the TLT-

Intervention. A coercive approach during the TLT-Intervention would probably have undermined her greatly. In November, Farida described how the consultants' friendly, easygoing manner encouraged her to persevere and try to learn through the TLT-Intervention. In January, she revealed that she had been afraid that consultants would judge her teachers' classrooms negatively because sometimes the junior teachers used Arabic instead of English. By May, however, she explained how she had eventually dared to engage with new ideas. Her fear had transformed into a sense of powerfulness through the gentle collaborative interactions she had engaged in:

I used to be afraid of new ideas. I didn't know how to apply them. Now I can try anything! ... Before, I felt I couldn't do it. Then I saw we could do whatever we wanted and the result would be very good... I found it simple, not hard [Maylnt].

\section{Summary of Farida's Case}

Farida's problems at the start of the TLT-Intervention were her lack of both confidence and motivation, partly due to inadequate encouragement experienced at work. It seemed that these factors were blocking her learning and development. However, she claimed that a mixture of non-coercive engagement with a range of others aided her to overcome her lack of confidence which in turn enhanced her motivation to learn and develop. She completed the TLT-Intervention with a new sense of powerfulness and authority that she had not known before which she then built on to pursue further development. 


\section{Discussion}

This article has explored how three case-study Senior Teachers developed professionally across the eight-month TLT-Intervention. The TLT-Intervention was based on the findings from previous research that collaborative interaction and a sense of self-direction were essential for fruitful learning outcomes (Belibas, Bulut and Gedik 2017; Earley and Porritt 2010; Leahy and Wiliam 2011; Philpott and Oates 2017; Stoll et al. 2006; Tannehill and MacPhail 2017). These aspects of learning were also at the heart of Vygotsky's theories about how learning and development occurred. This article has considered whether these three Senior Teachers used collaborative interaction and self-direction in their own attempts to learn and if so, how they used them, with what awareness and with what consequences.

In all seven of our cases, even when we first met them in September, these Senior Teachers displayed a conception of learning as larger than academic learning or learning how to carry out techniques. They all considered their role as teachers as being about developing people: who loved learning and could function in and contribute to their environments socially. This was perhaps surprising since their education system focused heavily on memorisation for exams.

How participants' perceptions changed regarding collaborative interaction

Without exception, these Senior Teachers came to appreciate in a transformative way, how much more they could learn from others than they had appreciated. They all started with good intentions, but by the end of the TLT-Intervention, they could clearly see that the potential for their own learning lay partly in the ideas of their more junior colleagues or pupils. Learning started to appear to them to be a two-way process (Brown et al 1993; 
Wells 2000). One important finding was that it was not only the content of what others said which had influence: their enthusiasm or creativity could provoke learning too. When the teacher from a more advantaged school saw how the less advantaged teacher still took on enterprising challenges, this boosted her own drive to learn (Hart, 2000).

Having their own views valued by others also inspired the Senior Teachers' learning (Mercer 2000). It seemed to give them confidence and help them feel that they had some professional authority. This was the case, even when appreciation came from less senior teachers. That was a transformational insight within the Egyptian system where only praise from those with senior authority roles tended to be valued (Hammad 2010). But when working as a team, as one member's activities were clearly successful, all members of the team felt driven to learn more. Unlike models of 'success' in the existing system, as the TLT supported each other, the group of teachers abandoned personal gratification in favour of mutual benefit (Rogers 1951, 283).

Another way that the case-study teachers described learning was by being demonstrated to or having a practice exemplified in real life. At the start of the TLT-Intervention, some of the Senior Teachers expressed the belief that it was their job to show junior teachers how to carry out tasks correctly. However, they later related that the 'coaching' approach promoted by the TLT-Intervention transformed this early belief. They came to notice how being asked by the consultants to express themselves, and being listened to, supported them to act proactively. Then, by exemplifying coaching behaviour themselves, they themselves learnt more from their colleagues while also supporting their colleagues' learning more. However, in order to make 'reflective interaction to flow freely without trying to impose her/his own values or wishes' (Shayer 2003, 481), time and space needed 
to be made systemically available for such coaching conversations. These commodities were in short supply in all the case-study schools, a lack that seemed to obstruct all teachers' learning.

Participants' perceptions of self-direction as a trigger for learning and a means for achieving their own goals

One strong message that came through our interviews was the enjoyment experienced by the participants during the TLT-Intervention meetings and activities, which enhanced their curiosity, innovativeness and creativity. As Vygotsky emphasised, volition and interest led their developmental process. In fact, it was this spark, this 'spirit' as Laila called it, that set learning into motion. It was this energy that led the participants to try to overcome the gap between their current and their desired capabilities. Participants all commented on how they had previously slipped into boring routines which the Intervention had shaken up. They all remarked that this flame was born out of their own volition, not as a result of rewards, punishments or threats (Niemiec and Ryan 2009). They had come to see why these latter motivators did not entice them to engage in the big and sometimes difficult process of learning. A good explanation lay in their experiences of the classroom observations made by their peers, in which they had chosen their own observers, whose views they had specifically requested. Because they themselves initiated these observations, they felt encouraged to make them useful and make changes based on the observer's comments. This was in stark contrast to the judgemental observations by supervisors that they were accustomed to.

This exercise of their own agency seemed to transform participants' sense of professional self and their confidence. As they directed their own actions and observed the changes they 
inspired, they seemed to feel more authoritative as professionals. Their professional identities transformed as they became entrepreneurs who drove their own learning agenda. This was perhaps the area in which transformation was most evident: participants seemed to move, in Paulo Freire's famous words, from spectators to actors, from followers of prescriptions to makers of choices, from silent participants to outspoken collaborators $(1972,25)$.

Participants noted that an important ingredient in this shift was the setting of a specific, clearly explained, shared goal in the presence of their colleagues who would provide ongoing support. It appeared that the setting of their owned and clearly identified goal, helped them to feel that they were progressing towards a new level of conceptualisation in relation to their professional practice. They came to notice the formation of new functions or the enrichment of existing functions, in relation to this goal, with the support of their Team. Prior to their experience in the TLT-Intervention, their work had seemed less purposeful. They had carried out routines but did not always know what they were working towards or why.

Once purpose was established, with collaborative support systems in place, the participants sought diverse opportunities for developing towards their goal. This drive to find every possible opportunity was especially clear in Saif's case. Rather than waiting for things to be done for them and to them, now the Senior Teachers sought ways to make things happen themselves. This may seem obvious to those of us who enjoy some autonomy in our work, but to the teachers in this study, it was largely a novel idea that learning had to start where the learner started and be subjected to the will of the learner. 
However, we questioned whether we had fostered a new hierarchy among the participants. The Senior Teachers reported that the consultants' guidance bestowed value and status onto all the TLT-Intervention activities. This in turn seems to have led some Senior Teachers' development to have become inextricably linked to the consultants' approval, a dependence which might be assumed to limit their capacity for self-direction. Yet, from a Vygotskian perspective, given the restrictive context within which these Senior Teachers worked, perhaps they were doing exactly what Vygotsky depicted: they were working with the demands and possibilities of the environment and making best use of these. They had found someone to interact with, who could provide a way to move beyond their experience of low status and low authority as teachers. And in the Egyptian case, status was easily bestowed through contact with 'native' English speakers. This would explain Saif's constant emphasis on having contact with native English speakers and the fact that all the teachers found it very encouraging when we, as TLT-Intervention consultants, physically visited their teachers at school. Perhaps this should be seen as a clear manifestation of proactive selfdirection itself, rather than dependence. An unquestioning acceptance of 'decisions from above' was a long-established cultural behaviour; by associating strongly with the Intervention consultants, the participants were perhaps using this culturally embedded custom to achieve their own, self-directed goals, even when these appeared different from the TLT-Intervention's goals.

It is against the backdrop of these deeply embedded hierarchical customs that the academic significance of this article needs to be considered. This research took place in the context of a middle-income country, where typically collaboration could be considered threatening within inflexible hierarchies of power; and conformity was emphasised to the exclusion of development (Hammad 2010). As in other recently independent nations, in Egypt there has 
seemed to linger 'a deeply entrenched culture of obedience and conformity... that compels the rights and privileges of the larger society over the individual' (Ab Kadir 2017, 237). None the less, the research vividly illustrates that personally fulfilling and developmental learning still occurred when the individuals within these constraints engaged in collaborative interaction with others in their environment; and when they directed their own ways forward. Although Vygotsky's views are Eurocentric and therefore not universally applicable, our research seemed to confound this exclusionary assumption. Despite hostile cultural tradition, despite obstructive locally-reinforced habits, when given the opportunities flagged up by Vygotsky, professional learning and development flourished, with the support of a More Knowlegable Other and a Team of colleagues.

\section{Acknowledgements}

Many thanks are due to the Senior Teachers who allowed us to research their practice over the course of the Intervention. Thanks are also due to Prof. Alex Moore and Dr. John Hardcastle for their very helpful comments on an earlier version of this paper.

\section{REFERENCES}

Ab Kadir, M. 2017. "Engendering a Culture of Thinking in a Culture of Performativity: The Challenge of Mediating Tensions in the Singaporean Educational System." Cambridge Journal of Education 47 (2): 227-246.

Bellibas, S., O. Mehmet, and S. Gedik. 2017. “Investigating Professional Learning Communities in Turkish Schools: The Effects of Contextual Factors.' Professional Development in Education 43 (3): 353-374.

BSA, British Sociological Association. 2002. Statement of Ethical Practice. http://www.britsoc.co.uk/media/27107/StatementofEthicalPractice.pdf 
Brown, A.L., and D. Ash, M. Rutherford, K. Nakagawa, A. Gordon and J. Campione. 1993.

'Distributed Expertise in the Classroom'. In Distributed Cognitions: Psychological and

Educational Considerations, edited by G. Salomon, ed., 188-228. Cambridge: CUP.

Carnell, E., J. MacDonald and S. Askew. 2006. Coaching and Mentoring in Higher Education:

A Learning-centred Approach. London: Institute of Education.

Chaiklin, S. 2003. "The Zone of Proximal Development in Vygotsky's Analysis of Learning and Instruction.'" Vygotsky's Educational Theory in Cultural Context 1: 39-64.

Earley, P., and V. Porritt. 2010. Effective Practices in Continuing Professional Development: Lessons from Schools. London: Institute of Education.

Fielding, M. 1996. 'Beyond Collaborative interaction: On the Importance of Community.' In Consorting and Collaborating in the Education Market Place, edited by D. Bridges and C. Husbands, 149-167. London: Falmer.

Freire, P. 1972. "Pedagogy of the Oppressed. 1968." Trans. Myra Bergman Ramos. New York: Herder.

Glaser, B. and A. Strauss. 1967. "Grounded Theory: The Discovery of Grounded Theory. Sociology: The Journal of the British Sociological Association, 12, 27-49.

Lincoln, Y. and E. Guba. 1985. Naturalistic inquiry (Vol. 75). London: Sage.

Hammad, W. 2010. “Teachers' Perceptions of School Culture as a Barrier to Shared Decisionmaking (SDM) in Egypt's Secondary Schools". Compare 40 (1): 97-110.

Hammad, W. 2016. Conflicting Road Maps: Cross-cultural Professional Development for Egyptian Educators. Compare: A Journal of Comparative and International Education 46 (2):

293-313. 
Hargreaves, E., M. Mahgoub and D. ElHawary. 2016. An Investigation into Improved Primary School English Language Learning in the Crowded Classroom: Pupils Explain what Teachers and Children Can Do to Make Progress (An Egyptian Case Study). Cairo: British Council. Hargreaves, E. and D. ElHawary. 2018. “Professional Development through Mutually Respectful Relationship: Senior Teachers' Learning against the Backdrop of Hierarchical Relationships". Professional Development in Education.

Hart, S. 2004. Learning without Limits. UK: McGraw-Hill Education.

King, F. 2014. "Evaluating the Impact of Teacher Professional Development: An Evidencebased Framework." Professional Development in Education 40 (1): 89-111.

Leahy, S., and D. Wiliam. 2011. “From Teachers to Schools: Scaling up Professional Development for Formative Assessment". In Assessment and Learning, edited by John Gardner. 2nd ed, 49-71. Thousand Oaks, CA: Sage.

Maxwell, J. 2012. Qualitative Research Design: An Interactive Approach. London: Sage. Mercer, N. 2000. Words and Minds. Oxford: Routledge.

Mezirow, J. 1990. How Critical Reflection Triggers Transformative Learning: A Guide to Transformative and Emancipatory Learning. San Francisco: Jossey Bass.

Niemiec, C., and R. Ryan. 2009. “Autonomy, Competence, and Relatedness in the Classroom: Applying Self-determination Theory to Educational Practice". School Field, 7 (2): 133-144. Philpott, C., and C. Oates. 2017. "Teacher Agency and Professional Learning Communities; What Can Learning Rounds in Scotland Teach Us?." Professional Development in Education 43 (3): 318-333. 
Pratt, N. 2007. Democracy and Authoritarianism in the Arab World. Boulder, CO: Lynne Rienner Publishers.

Rogers, C. 1951. Client-centered Therapy: Its Current Practice, Implications, and Theory. London: Constable.

Shayer, M. 2003. “Not Just Piaget; Not Just Vygotsky, and Certainly not Vygotsky as Alternative to Piaget.'" Learning and Instruction 13 (5): 465-485.

Stoll, L., R. Bolam, A. McMahon, M. Wallace, and S. Thomas. 2006. “Professional Learning Communities: A Review of the Literature." Journal of Educational Change 7:221-258.

Tannehill, D., and A. MacPhail. 2017. "Teacher Empowerment through Engagement in a Learning Community in Ireland: Working across Disadvantaged Schools." Professional Development in Education 43 (3): 334-352.

Van der Veer, R., and Valsiner, J. 1991. Understanding Vygotsky: A Quest for Synthesis. Oxford: Blackwell.

Vygotsky, L. S. 1978. Mind in Society. London: Harvard University Press.

Vygotsky, L. S. 1962. Thought and Language (E. Hanfmann \& G. Vakar, Eds. And Trans.). Cambridge, MA: MIT Press.

Wells, G. 2000. 'Dialogic Inquiry in Education: Building on the Legacy of Vygotsky'. In Vygotskian Perspectives on Literacy Research, edited by C.D. Lee, 51-85. Cambridge: Cambridge University Press.

Yandell, J. 2007. “Investigating Literacy Practices within the Secondary English Classroom, or Where is the Text in this Class?." Cambridge Journal of Education 37 (2): 249-262. 


\author{
Exploring collaborative interaction and self-direction in Teacher Learning Teams: case- \\ studies from a middle-income country analysed using Vygotskian theory \\ Dr. Eleanore Hargreaves, UCL Institute of Education, 20 Bedford Way, London WC1H OAL \\ Dr. Dalia ElHawary, Department for Curriculum and Instruction, Alexandria University, Egypt.
}

\begin{abstract}
This article explores teachers' learning from a Vygotskian perspective which emphasises collaborative interaction and self-direction. The article describes case-studies of three Senior Teachers in socio-economically disadvantaged Egyptian primary schools where collaboration and self-direction were systemically discouraged. It analyses how, through a teacher development Intervention, the teachers learned to use collaborative interaction to support their own learning and felt more creative, authoritative and powerful after being guided to exercise self-direction.
\end{abstract}

\title{
BACKGROUND AND THEORETICAL FRAMEWORK
}

Extensive literature on sustainable professional development has indicated that participating teachers must have capacity for both collaborative interaction and selfdirection (Leahy and Wiliam 2011). This article re-explores these aspects of learning in the Egyptian context where, as in many middle and low-income countries from Nigeria to Jamaica to Myanmar, neither collaborative interaction nor self-direction have systemic support (Hammad 2010). The article offers a novel approach to exploring teacher development, through a Vygotskian lens. Vygotsky's $(1986 ; 1978)$ theories about how people learn were originally applied to pupils' learning rather than teachers' (e.g. Yandell 2007). In the case of pupils, the target is the development of academic (or scientific) concepts. However, for adult teachers, learning and pedagogy become the focus instead. As 
our professional development Intervention proceeded, Vygotsky's theories proved to be significant. 


\section{Academic significance of the article}

This article provides case-studies of the professional learning and development of three Senior Teachers in socio-economically disadvantaged Egyptian primary schools who took part in the TLT-Intervention. It investigates their own views of learning and development. It explores how they described collaborative interaction and self-direction influencing their professional learning across the eight-month Intervention. By professional learning, we borrow Rogers' (1951) definition of change as in 'the organisation of self' (390): that is, of a shift in how they perceived and enacted their own learning and their support for others' learning. Where their change seemed significant and irreversible, we refer to their learning as transformative, in Mesirow's (1990) sense:

Becoming critically aware of how and why our presuppositions have come to constrain the way we perceive, understand and feel about our world (14).

Transformative learning involved re-defining themselves, in relation to others, thereby potentially moving beyond localised learning to long-term development.

The relevance of this research lies in its task of more fully understanding the complex interplay between individual teachers' professional development and Vygotsky's emphasis on collaborative interaction and self-direction. The findings will be particularly relevant to the many countries of the world where teachers' collaborative and self-directed learning are dismissed in favour of conformity to those with more powerful hierarchical positions. Some authors suggest that such a hierarchical approach has prevailed in Egypt (and other countries in the global south) partly because beliefs there about the individual's role in society are 'diametrically opposed to Western or at least mainstream US assumptions' (Atkinson 1977, 80, cited in Ab Kadir 2017, 242). Hammad $(2010,108)$ described how 
Egyptian teachers' fears of 'chaos' and 'conflict' seemed 'to be rooted in a greater societal emphasis on social cohesion and harmony'. Pratt (2007) proposed that, for ex-colonial countries such as Egypt, this was a result of previous subjugation. Thereby, there has seemed to linger 'a deeply entrenched culture of obedience and conformity... that compels the rights and privileges of the larger society over the individual' (Ab Kadir 2017, 237). These assumptions tend to be in tension with constructivist models of teachers' learning, where teachers' creativity and diversity may be more highly valued than conformity to existing structures.

\section{Professional development Intervention using Teacher Learning Teams [TLTs]}

The processes which we call here the "Intervention" included the introduction into six Egyptian primary schools the system of Teacher Learning Communities [TLCs] or "Teacher Learning Teams" as they were re-named in Egypt (hence "TLTs"). We adapted Leahy and Wiliam's (2011) design for TLCs but replaced their focus on formative assessment with learning and teaching English as a foreign language. After spending time in Egyptian primary classrooms (see Hargreaves, Mahgoub and Elhawary 2016), as a team of researchers, we perceived that some essential ingredients for professional learning were missing from teachers' experiences: specifically, opportunities for collaborative interaction; and for directing learning according to individual need and interest. Recent reviews of teacher professional development suggest that TLCs (or TLTs) embody characteristics closely associated with sustained improvements in teachers' development (Belibas, Bulut and Gedik 2017; Earley and Porritt 2010; Leahy and Wiliam 2011; Philpott and Oates 2017; Stoll et al. 2006; Tannehill and MacPhail 2017). This improvement is attributed to the fact that TLCs are founded on teachers identifying their own focus for, and process of, professional development. In this model, teachers are expected to collaborate with each other in order 
to learn; input from beyond the school is also helpful, although the main site for development is the school. None of these foundational aspects characterised teachers' planned learning in Egyptian schools (see also Hammad 2010).

\section{Vygotsky's theories about collaborative interaction}

Collaborative interaction among teachers has been frequently described as a key feature of successful professional development (Bellibas et al. 2017; King 2014; Tannehill and MacPhail 2017) and is central to the structure of TLTs [TLCs]. In Vygotskian terms specifically, the term 'collaborative interaction' refers to any situation in which the learner is being offered interaction with another person or people. This person or people provide support for a problem that the learner wants to solve: '... through demonstration, leading questions, and by introducing elements of the task's solution' (Vygotsky [1987, 209] in Chaiklin [2003, 54]). How much each teacher could benefit would depend on their existing levels of perception, thought and will. As Chaiklin $(2003,49)$ suggested, existing levels would reflect 'institutionalized demands and expectations that developed historically in a particular societal tradition of practice'.

\section{Vygotsky's theories about self-direction}

Reviews of teacher development through TLCs (e.g. Philpott and Oates 2017; Tannehill and MacPhail 2017) indicate that effective teacher professional development depends on teachers exercising proactive self-direction; in particular, it is effective when a learning need is identified as important by participants themselves and action taken and supported accordingly. This is an often-overlooked aspect of teacher professional development, particularly in countries like Egypt where theoretical, university-based training still has the dominant place in the hierarchy of valued knowledge (see Hammad 2016). The organisation 
of TLTs, in contrast, focused explicitly on strategies identified by teachers themselves as useful for their own classrooms.

Vygotsky emphasised that volition and interest led the developmental process. Chaiklin $(2003,47)$ described how, from a Vygotskian view, learners noticed their current capabilities and compared these to their 'needs and desires, and the demands and possibilities of the environment'. In trying to overcome this gap between current and desired capabilities, and to realize particular action, the learner willingly engaged in tasks and interactions which allowed 'the formation of new functions or the enrichment of existing functions' $(2003,47)$. Teachers thereby perceived themselves more as subjects than as objects of development (Philpott and Oates 2017).

As Vygotsky stressed, self-direction may begin during collaborative interaction: through speaking with others, any simple action was raised to a higher level and subjected to the power of the learner who 'puts upon the action the stamp of will'. It was this stamping, during interaction, that made the learner's action 'free' (Vygotsky 1933, in van der Veer \& Valsiner 1991, 345). In other words, reflection by the individual could be spawned from collaborative interaction (Shayer 2003, 481) which led to freely adopted action. Rewards, punishments or persuasion would not substitute the teacher's own volition and interest (Niemiec and Ryan 2009). Self-direction therefore suggests creating, or controlling for oneself, a situation, by taking an informed initiative, rather than waiting for things to be done for or to oneself. Important tools that support the taking of initiative are collaborative interaction with peers; as well as the teacher's own observation of how their actions are making change which 'can give teachers an authoritative basis for their views' (Philpott and Oates 2017, 327). However, as Philpott and Oates (2017) point out, in a tightly controlled 
system, such as the Egyptian system, these 'alternative discourses' may have to be learnt from beyond the school (327).

\section{Application to the research}

In the TLT-Intervention on which this research was based, the researchers led the Intervention (while at the same time carrying out the research on the Intervention) as 'More Capable Instructors'. They aimed to awaken 'a variety of internal developmental processes' in each Senior Teacher through collaborative interaction during meetings (Vygotsky [1978, 90] cited in Shayer $[2003,471])$. Collaborative interaction implied the valuing of each teacher's insights and contributions to others' learning. In our TLT-Intervention, this unselfish respect for others' aspirations, without thought of personal gratification, was a particular challenge for Senior Teachers, in a context where participants often faced fierce competitiveness among colleagues who were used to being oppressed by those with power over them (see also Hammad 2010). Our research therefore explored whether teachers could learn and develop professionally despite these tensions, benefiting from collaborative interaction as well as self-direction.

\section{RESEARCH DESIGN}

The following sections describe the principles according to which this research was conducted. It used an interpretivist approach. Without denying the existence of one 'reality' underlying people's interpretations, we were interested in exploring how this reality was constructed by seven Senior Teachers in Alexandrian primary schools and how we could make sense of these constructions (Guba and Lincoln 1985; Maxwell 2012).

\section{Sample}


Our research sample of Senior Teachers consisted of all the teachers signed up for the TLTIntervention: four female teachers from three National Institute schools, which were government schools with some private funding. We also worked with three male teachers at AlAzhar schools which were government-controlled with support from AlAzhar university and mosque in Cairo. All participating schools were relatively disadvantaged socioeconomically, but the AlAzhar schools took some of Egypt's poorest children. The Senior Teachers involved were those who had been teaching for an extended period, who monitored the learning and teaching of less experienced teachers.

Context of the research: the Intervention

Funded and directed by the Education Development Trust, we as consultants led the Intervention as a team of Egyptian and English educators (two of whom are authors of this article, one Egyptian, one English). The TLT-Intervention aimed to support the learning and teaching of English. We academic researchers, however, also used the TLT-Intervention as a means to investigate teachers' professional use of collaborative interaction and selfdirection.

As described also by Hammad (2010), there tended to be a lack of trust among Egyptian teachers, as well as a lack of experience, in making professional decisions. Therefore the following three initial training sessions for the Senior Teachers were considered essential for the success of the TLT-Intervention and took place towards the end of 2015:

1) Two days on leadership generally, to explore alternatives to the dominant autocratic model;

2) Two days on "Coaching" specifically (Carnell, MacDonald \& Askew 2006). This was a leadership approach which entailed empathetic listening to others rather than the giving of 
instructions or making demands (as in the normal image of "leadership"). This approach demanded a more equal relationship between leader and led and assumed more selfdirection on the part of the led; and

3) Two days on leading TLTs as communities in which the Senior Teacher and her/his Team of teachers shared/developed practices and reflections.

From each school, one Senior Teacher attended initial training sessions.

In February 2016, we then hosted a workshop to which Senior Teachers brought all their TLT teachers to share and demonstrate their new ideas with others: this turned out to be an extremely unusual but highly appreciated occurrence in their context (see also Hammad 2016). In March, the seven Senior Teachers made a presentation at an international conference in Jordan: this was also a rare and valuable opportunity that was normally left only to those in higher hierarchical positions.

Apart from these discrete training sessions, the seven Senior Teachers met together every month to discuss and reflect on how their professional development was progressing; and how their support to other [TLT] teachers' professional development was flourishing under their guidance. Each Senior Teacher had been initially observed by one consultant as they carried out an innovative five-minute 'action' in their classroom which was integrated to support their tightly-prescribed syllabus. The action was planned on an Action Plan to meet self-identified goals. Goals included, for example, improving speaking, focusing on struggling pupils, making learning more active.

TLTs had been set up in each school by the Senior Teacher. In mid-November, each Senior Teacher had led their first TLT meeting, supported by consultants. After this TLT meeting, the TLT teachers had also tried out their own innovative five-minute actions in their English 
classrooms. Teachers observed each other during these actions. In each subsequent TLT meeting, the Senior Teacher invited the group to:

- Describe, then analyse as a team, what happened when they tried out the planned five-minute action in their classroom.

- Decide on a revised Action Plan for the forthcoming month and decide which colleague would observe it.

As consultants, we provided ongoing input to support Senior Teachers' coaching skills; and attended TLT meetings and observed classrooms if invited.

Data collection during the Intervention

In this article, we present the cases of only three Senior Teachers who led TLTs, drawing exclusively on interview data. We refer informally also to our attendance at their TLT meetings in their schools. We chose to use our available space here to focus in detail on three participants rather than to collate our findings across all seven, because the development journey itself, and each Senior Teacher's specific environment, were important for understanding how they used collaborative interaction and self-direction. The decision also reflects our belief that each teacher's journey across the year was original and whole in itself (Fielding 1996) and needed to be narrated holistically. Findings relating to all seven Senior Teachers can be found elsewhere (Hargreaves and ElHawary 2018).

The three Senior Teachers we selected did, however, represent all seven as much as possible. For example, they included two women and one man of different ages, who came from three very different schools and who responded diversely to the TLT-Intervention activities. They were (using pseudonyms): Laila, Saif and Farida. We carried out three indepth interviews in November, January and May, 2015-16, with each Senior Teacher plus an 
additional one with Saif in September 2015. All interviews were transcribed and translated from Arabic by the dedicated Intervention translator, in constant dialogue with one author of this paper (who is herself bilingual).

\section{Data analysis}

There were several stages to our data analysis, which the two main researchers carried out collaboratively. As interviews were transcribed, we studied the transcriptions and prepared our next interview schedule accordingly [September, November, January, May]. By May, we were very familiar with the data. Basing our strategy on Grounded Theory (Glaser and Strauss, 1967), we then looked inductively for themes raised in all the interviews. Our focus had always been collaborative interaction and self-direction, but we noticed a range of unanticipated aspects to these as they developed across the Intervention. Other themes emerged in interviews too. We therefore drew aside those instances where collaborative interaction and self-direction were clearly addressed and re-examined these texts for subthemes. We found that often these sub-themes linked directly to our understanding of Vygotsky's theories about learning. For example, our sub-themes included:

- Appreciation/encouragement;

- Enjoyment, curiosity, innovation, creativity;

- Confidence in self/gaining a sense of authority;

- Teamwork/listening to others;

- Consultants' demonstration.

We therefore re-analysed the dataset, with these sub-themes in mind. This time, we looked specifically for how each of our participants talked about the sub-themes we had developed. During this process we selected those three leaders whose journeys we 
believed would best represent the whole group's professional development across the TLTIntervention. [After each citation below, the month of interview is noted to highlight chronological progression e.g. 'Janlnt' denotes an interview carried out in January].

\section{Ethical issues}

This research, both in its design and fieldwork, adhered to the BSA ethical guidelines (2002). We explained to Senior Teachers that the purposes of our research were to explore means for developing English teaching. It appeared that they were not worried about the specific details of the research but most interested in working with academics from outside their schools who could give them support for English teaching. They had ample opportunities to withdraw from the research which ran from September 2015 to May 2016; but they were all keen to take part and signed their consent willingly. Their identities have been disguised so that only the participants themselves could detect their real roles.

\section{FINDINGS}

\section{Laila}

Laila was a mature teacher of Year 6 pupils in an English language school. Laila was an interesting case because, when she started the TLT-Intervention, she seemed professional and well-organised in terms of her own learning, teaching and leadership. However, during the TLT-Intervention, she noticed significant progress in all three. The goal of Laila's own five-minute activities for pupils was to improve the learning of her lowest-attaining pupils. She therefore experimented with differentiation by giving pupils a choice of task, without deciding for her pupils who should choose which level of task. This was extremely innovative in her context.

\section{Laila's learning through and about collaborative interaction}


Laila's description of her collaborative interactions at the start of the TLT-Intervention suggested that, unusually, she already had interactive relationships with her teachers and pupils and considered their contributions as sources for her own learning. As Senior Teacher, she consulted even her youngest teachers and gave them choices. She also valued collaborative interaction with pupils, parents and the wider community, including those outside the system:

I like the new and crazy ideas from the younger generation... I like to take feedback from parents by asking our relatives, friends, neighbours; and getting their feedback. They are distant from the process itself so their feedback can be very helpful [Novint].

During the TLT-Intervention, Laila felt that she gained by conversing with teachers from the different Intervention schools because she noticed that everyone had similar problems and this made her feel 'normal'. However, in November, she told us that teachers from her school could not learn from the teachers in the AlAzhar schools because English there was of a lower level. However, after interaction with these teachers at the February workshop, Laila's view shifted:

[My teachers] were very affected by the [AlAzhar] groups. They saw in the videos how basic their facilities were and how weak their students were and they still managed to do something! This really motivated them [Maylnt].

Laila also changed how she collaborated with her teachers. Unlike any of the other Senior Teachers, prior to the TLT-Intervention she already gathered together her teachers in a weekly meeting where they discussed more than just the syllabus. In November, she described those existing meetings as very useful because in them she was able to find out 
'what people are thinking and feeling' [NovInt]. In these meetings, she had always treated her teachers as colleagues, reflecting her developmental rather than hierarchical perspective. However, she perceived the situation as follows: 'They sit with me and I make things easier for them by telling them what to do' [NovInt]. By May, she displayed a difference: now, she emphasised that she learnt more from her teachers than they gained from her. In particular, they gave her encouragement. She suggested that the learning by each person, including herself, exceeded that which could have been attained by each individual in isolation. She explained:

As a leader, I learnt how I can help the people around me and how they can help me. Actually, they might have helped me more than I helped them... I felt we were really helping each other. If that could occur more often, what would happen? We were four, and we all benefited. If that had been applied more widely - imagine the effect!

Laila also described the common phenomenon in the Egyptian context, that many teachers did not know how to collaborate and sometimes chose to work alone because it was easier. As she came to see how others enhanced her own learning, she had changed the mentality among her own teachers and was now hoping to prepare the pupils in their classes for a more collaborative outlook that they could take with them into adulthood.

\section{Laila's learning through and about self-direction}

Laila illustrated self-direction as 'new spirit' whereby, because of the TLT meetings, she and her teachers came to see a clear development goal and feel inspired to reach that goal [Maylnt]. The 'new spirit' often included enjoyment and curiosity; and was closely allied to innovation and creativity. In Laila's view: 
Anything that doesn't change will fail. If you don't develop it, it will die. You must innovate in everything or it won't have spirit ... Over time, teaching the same thing, you get bored of what you are doing. It becomes simply a routine... I used to use the same activities each time. I was not creating anything. I started after the TLTIntervention to think of other things [Maylnt].

She described how innovation might increase exponentially, moving teachers from choosing just how to teach to deciding how and what to teach. This illustrated Vygotsky's idea of gradual independence from a More Capable Instructor. In addition, and in contrast with local tradition, Laila felt that older teachers needed to capture the spirit of self-directed experimentation from their younger colleagues:

Those who have been teaching for 10 to 15 years are stuck and need to go to courses and need to widen their horizons. They need to get out of their staffrooms and meet new people and discover new ideas [Maylnt].

However, she was clear that, to ignite this spirit, the school's administration needed to give teachers the chance to choose which programmes they wanted to attend rather than imposing training programmes on them. The fact that the current TLT-Intervention had been voluntary was a vital part of its benefit. Laila seemed to suggest that the spirit of innovation ignited a determination to improve; and as improvements occurred, confidence increased which bred further spirit and stronger determination.

For herself, she found the experience at the conference in Jordan encouraging especially after Senior Teachers 'stood up and did our own things' [Maylnt]. Then she started to feel that she could do workshops for other teachers herself, because of a new sense of her own authority. In any workshops that she proposed to give, she said that she would use the 
model demonstrated by the TLT-Intervention: allowing participants to identify their own needs; making sure that they were engaged and enjoying the workshop. She was building on her own growing awareness of the need for choice, participation and enjoyment in development:

First, I will give them the choices for what topic I will talk about. Then think about the steps of the presentation. And prepare handouts so the presentation isn't boring. And think about how to get them to participate [Maylnt].

She claimed that choice, enjoyment and participation were essential to her TLT teachers' learning too, and they experienced these when doing peer observations. Laila came to see that the unannounced lesson observations that she used to conduct as Senior Teacher were neither useful nor fair. Now she perceived that each teacher should choose who observed them, and also which lesson, if they were actually going to learn from the experience.

Laila explicitly expressed how, during the TLT-Intervention, she and her teachers gradually progressed towards a new level of conceptualisation in relation to professional practice. This included formation of new functions and enrichment of existing functions. As she summarised it: 'When [people] work in pairs and groups, they get lots of ideas. Or, the ideas were already there, but they needed to bring them out' [Maylnt]. She saw how through processes of collaborative interaction and self-direction, she could overcome gaps between her current and her desired capabilities. For example, when she became Senior Teacher, she found herself responsible for a whole department but had not received professional training to grasp her new responsibilities. Supervisors visited from the Ministry of Education but came 'just to do paperwork'. It was the TLT-Intervention which helped to clarify for her how to be a better leader of teachers by supporting her to use certain tools. This was a 
classic example of how guidance from a More Capable Instructor [in this case, the Intervention consultants] allowed her to achieve more with their support than she would have done alone, as she crossed through her Zone of Proximal Development (Vygotsky 1978). In another example, in relation to coaching, she noticed that she was already doing coaching when the TLT-Intervention began. But she reflected:

I wasn't very aware of the way to do it. I was doing it randomly. But you made it more comprehensive and organised. You organised my ideas [Maylnt].

\section{Summary of Laila's Case}

In Laila's case, learning meant nurturing 'spirit' which was ignited by collaborative interaction, choice, enjoyment and participation, which led to an unfolding sense of selfdirection and awareness of her own authority. The guidance she received from the consultants took the form of demonstration and clarification of concepts and practices that had been vague in her consciousness. Consultants and other teachers also provided encouragement and stimulus for her learning and development.

\section{Saif}

Saif was a male teacher in his thirties who taught middle school girls in one of AlAzhar's Islamic schools; and was Senior Teacher in their primary school too. He was an enthusiastic member of the TLT-Intervention's cross-school Senior Teachers' group and never missed sessions. The goal of the five-minute activities that he developed for his pupils was to improve his pupils' interaction in English. The activity consisted of pupils writing their own short play-scripts and performing them in class. This activity seemed to revitalise his classes 
and his own learning significantly. However, Saif's TLT appeared somewhat fragmented and keeping it coherent became a struggle.

\section{Saif's learning through and about collaborative interaction}

Saif described having 'spiritual aims and motivation' [Janlnt] and explained that the Qur'an itself eulogised education as a means for improving people's lives. One reason for caring particularly about English teaching was so that his students could 'explain Islam and Islamic civilisation to others' [Maylnt]. He also believed that Egyptians could learn from Englishspeaking countries and people. Saif talked extensively about connecting with other people to 'exchange experience' [Janlnt]. He described how at school, before the TLT-Intervention, he was not asked to express his opinions, there were no discussions and, most importantly, no shared educational goals towards which to strive. Yet, he himself seemed to learn from a wide range of others in his environment, despite this lack of systemic encouragement. Saif described how other teachers in his TLT, and also of different subjects in his school, helped him think about changing his teaching. Over the course of the TLT-Intervention, he came to realise that students too had a lot to offer him for improving the way he taught.

The Intervention consultants' apparent confidence in him and exchange of ideas with him also helped him change. His exposure to other English speakers from a range of countries during the conference in Jordan, also motivated him as he perceived himself to belong to a wider community of English speakers. In contrast, not many teachers felt valued in Egypt, according to Saif, and they therefore lacked confidence and also lacked the will to develop. He described the teacher as being 'the lowest person in the state... perhaps less than the rubbish collector' [Janlnt]. However, Saif suggested that his increased sense of professional authority was due to the TLT-Intervention and due to the educational research that 
underpinned it. He believed that the 'academic' input of the TLT-Intervention, based on research, gave the TLT-Intervention power, because teachers had learnt 'something real' [Janlnt].

Saif recounted that the TLT-Intervention allowed him and his teachers to benefit from teamwork and so progress towards development. Already in September, Saif himself advocated an egalitarian view of teamwork as essential for learning. Whilst he recognised his approach as unusual for his culture, his insight was that an open exchange of ideas had to happen in order for learning to flourish:

We can work together and see the strengths and weaknesses among us and try to fix them... I might suggest a way of teaching as an idea: not as an order. We might do brainstorming: I say my ideas, the teachers say their ideas. We consider what emerges from it; and what will be in the best interests of the students [Seplnt].

This unusual openness to others' views even extended later into his classroom, despite the hierarchical traditions of his teaching-learning environment. He mentioned several times that he aimed to nurture a family-like culture in his classrooms where pupils and the teacher learnt from each other on a continuous basis.

Saif recognised the role of demonstration in the consultants' support for his own learning as part of a different 'family': the group of the Senior Teachers from the six different schools. It is fascinating that he attributed the 'family approach' to the consultants' greater experience:

The family spirit - we [Senior Teachers] felt like a family. This encouraged us a lot. There wasn't a sense that anyone was inferior... I learnt it from you and your academic background. You supported us like your younger siblings. So, we were able 


\section{Saif's learning through and about self-direction}

Saif was already very aware that learning should start where the learner was positioned socially and psychologically. He saw clearly that when learners perceived their learning as 'personally meaningful' (Rogers 1951,427 ) they made the effort to progress. Saif could obviously see Vygotsky's point that learning must be subjected to the will of the learner. He saw that coercion blocked development:

The best thing [about the TLT-Intervention] was that you didn't force anyone to participate. If I was forced to join, I wouldn't participate well. When you feel you are there by choice, this makes you want to try. We felt we could go and try, and we didn't have to continue if we didn't like it. So we had nothing to lose. There were no penalties for not joining... When you are forced to attend, you just sit there, and you won't apply what you hear [Maylnt].

Saif noted that when his TLT teachers wanted to learn and then got the support from him as Senior Teacher, then it would happen: so long as he gave his support willingly without hope of personal gratification. Saif told us about the success of peer observations in which each teacher chose who would observe them, as they practised a new teaching activity, and looked only at the points requested by the practising teacher. These helped teachers to think of ways to improve their practice. This contrasted with past observations, whereby supervisors had deliberately looked for weak points in order to assert their superiority, thereby tending to block development. 
However, in order to develop their teaching approaches fruitfully, Saif reminded us that he and his teachers needed more time, more space, more support from the school administration and, most importantly for Saif, they needed to remain in one school for a predictable length of time to build up collaborative relationships. Saif suggested that five years would be an appropriate amount of time for genuine change to happen. Significant change could not occur in his own situation where he was working in two schools at once and could be transferred to another at any time. During one TLT in Saif's school, we saw a young teacher being taken away from the TLT to attend a different training session, against her will and against Saif's will. This disrupted the group's collaborations and reminded Saif of the systemic limitations to self-direction.

In relation to the importance of the learner's own will as the driver of learning, Saif mentioned on numerous occasions how sharing a specific goal inspired his own and his teachers' drive to learn. Choosing and clarifying a goal collaboratively seemed to open him up to richer interactions in order to achieve his goal. One way to support the achievement of this agreed goal was by teachers asking each other questions:

The most useful thing [in the TLT] was that everyone could ask their questions and get answers. If someone, for example, had a problem controlling their class, everyone would suggest an idea. We would get new and real-life ideas. We weren't working alone. We had set steps to follow. We were focused on one point [Maylnt]. In order to learn, Saif worked with the demands and possibilities of all aspects of his environment and tried to make best use of these. He talked about proactively researching 'new developments' in pedagogy, online. He also constantly asked us whether we as consultants could provide him with more English language and pedagogical training. We did 
note that Saif sustained some deference to foreigners' authority which he perhaps associated with the authors of the educational research he valued. While approval from any person in a high position was greatly valued in Saif's system, approval from 'native' English speakers was especially desirable for Saif. Saif explained that his pupils waited eagerly for our visits to their school because of the opportunity of being seen by fluent English speakers. On each visit by consultants to his school, many photos and videos were taken and courtesies exchanged, sometimes to the point of obstructing formal learning. At first we tried to avoid being given this special treatment, but on reflection we wondered whether it was actually one aspect of Saif working with the demands and possibilities of his environment and making best use of these. Saif was quick to point out that he would not necessarily import foreigners' ideas wholesale into their system. He added, 'We might change them to suit our circumstances and materials'. However, it was clear that collaborative interaction with fluent English speakers was an important means towards his developmental goals. And it was also a satisfaction of that goal itself.

\section{Summary of Saif's Case}

In summary, Saif expressed a view of learning as leading to a higher development of himself as a person, in terms of his authority, knowledge, ways of supporting others and as part of an English-speaking community. While he was already a collaborative professional when the TLT-Intervention started, he told us that he had learnt to value collaborative interaction further during the Intervention as he saw how it supported him to engage with and listen to a range of insightful views. He also began to believe in the power of his own self-directive capacities as he gradually perceived their effects. Despite many systemic obstacles to his collaboration and self-direction, Saif became extremely driven during the TLT-Intervention 
to achieve his ambitious, but strategic, goals of becoming an authoritative, supportive leader and teacher with a good command of the English language; and he pursued all the means to learning that he could access.

\section{Farida}

Farida was a female teacher in her thirties who taught Year 6 in a small National Institute school which prioritised English. She had two teachers in her TLT who seemed committed to Farida's leadership and to the TLT, although unfortunately one of them was on sick-leave for some time during the TLT-Intervention. Farida had a low profile initially but nearer the end of the TLT-Intervention, she seemed suddenly to perceive learning and teaching differently and take a more active role. The five-minute activities she developed focused on the goal of improving writing in English. She experimented in using groupwork in class for creative writing. A turning point for her was when she realised that pupils did not need to copy lists from the black-board and that collaborative groupwork was a better use of time.

\section{Farida's learning through and about collaborative interaction}

Farida was clear that for her pupils, learning was more than passing exams but she felt pressured by parents who did not share her vision. She believed that learning English included interacting in English as well as developing personal skills such as decision-making and supporting peers. Her own most valued learning and development goal was to act as a motivational source to others:

The [Senior Teacher] sets the atmosphere from the beginning. If they don't do this, there won't be any collaborative interaction. We have to set the atmosphere and try to collaborate. This will result in new ideas and development [Maylnt]. 
One of Farida's most significant learnings was discovering that discussion of ideas was developmental: for herself in Senior Teacher meetings; for her teachers in TLT meetings; and for pupils in lessons that incorporated groupwork:

I wasn't convinced by peer learning. I didn't understand how it could work. But it really worked. Sometimes they were able to explain to each other better than I was... How do they learn from each other? I didn't know they could learn from each other! [Maylnt].

Farida was emphatic about how supportive to her own learning the cross-school Senior Teacher meetings were. She had never sat with teachers from other schools more than in a one-day training event. She came to realise that they all had similar difficulties but that it was possible to negotiate ways of dealing with these. She became very motivated when she saw how driven and enthusiastic teachers from the AlAzhar schools were, which she described as 'those who have the least facilities in the world' [Janlnt]. She began to acknowledge to herself that her school was more privileged than theirs and that she actually had more support than they did, thereby redefining how she perceived her own position; and also giving her hope. In fact she started to see that her teachers were also doing valuable activities like the teachers in other schools.

This learning boosted Farida's self-confidence and her confidence in her teachers. She told us that this seemed to affect teachers of other subjects in her school too, who were 'curious about what we were doing'. She also felt connected to a much wider, highly respected community of English teachers, after making the presentation at the international conference in Jordan. As she expressed it: 'All of this added to me' [Maylnt]. In other words, these factors changed how she viewed herself professionally in relation to others. 
One aspect of learning that was important for Farida was observing the impact of her actions among her teachers and pupils. This was the basis for her increasing confidence and sense of authority which led, in turn, to further action. She perceived that this was because she was 'solving real problems'. In terms of how Farida perceived support to be provided for her own learning, she saw a significant role for 'experts' outside school. She appreciated the consultants' visits very highly but wanted more of these and more direction from consultants. Even at the end of the TLT-Intervention, she continued to ask consultants to provide ready-made pupil activities, even though at other times she recognised the importance of self-direction in her own learning, as described below.

An important aspect of her learning was having a specific, shared goal and feeling that she could reach it, with support. When she first started leading TLTs, she thought there would be little to talk about but then: '... Found we talked about many important things' [Maylnt]. What made discussion powerful for learning, she claimed, was that it was a very focused discussion with each person working towards the same goal. This contrasted with the fragmented system she experienced beforehand [Janlnt].

Farida described perceiving her teachers in a different, less critical way than before:

After I went to Gamila's class and saw her classes and how the students reacted to her, I respected her a lot more. Why had I limited her role and not realised how good she was? ... She also had new ideas ... She developed the ideas. I don't have these ideas! My view of my teachers changed [Maylnt].

Farida also mentioned the important role of appreciation. Her TLT teachers were motivated by the fact that, when presenting their work among colleagues at the February workshop, Farida encouraged her TLT teachers by mentioning all their various achievements. This was 
something that she reported her own school's administration did not do well but which could have encouraged her own development.

\section{Farida's learning through and about self-direction}

It was noticeable that Farida lacked confidence in herself at the start of the TLT-

Intervention. A coercive approach during the TLT-Intervention would probably have undermined her greatly. In November, Farida described how the consultants' friendly, easygoing manner encouraged her to persevere and try to learn through the TLT-Intervention. In January, she revealed that she had been afraid that consultants would judge her teachers' classrooms negatively because sometimes the junior teachers used Arabic instead of English. By May, however, she explained how she had eventually dared to engage with new ideas. Her fear had transformed into a sense of powerfulness through the gentle collaborative interactions she had engaged in:

I used to be afraid of new ideas. I didn't know how to apply them. Now I can try anything! ... Before, I felt I couldn't do it. Then I saw we could do whatever we wanted and the result would be very good... I found it simple, not hard [Maylnt].

\section{Summary of Farida's Case}

Farida's problems at the start of the TLT-Intervention were her lack of both confidence and motivation, partly due to inadequate encouragement experienced at work. It seemed that these factors were blocking her learning and development. However, she claimed that a mixture of non-coercive engagement with a range of others aided her to overcome her lack of confidence which in turn enhanced her motivation to learn and develop. She completed the TLT-Intervention with a new sense of powerfulness and authority that she had not known before which she then built on to pursue further development. 


\section{Discussion}

This article has explored how three case-study Senior Teachers developed professionally across the eight-month TLT-Intervention. The TLT-Intervention was based on the findings from previous research that collaborative interaction and a sense of self-direction were essential for fruitful learning outcomes (Belibas, Bulut and Gedik 2017; Earley and Porritt 2010; Leahy and Wiliam 2011; Philpott and Oates 2017; Stoll et al. 2006; Tannehill and MacPhail 2017). These aspects of learning were also at the heart of Vygotsky's theories about how learning and development occurred. This article has considered whether these three Senior Teachers used collaborative interaction and self-direction in their own attempts to learn and if so, how they used them, with what awareness and with what consequences.

In all seven of our cases, even when we first met them in September, these Senior Teachers displayed a conception of learning as larger than academic learning or learning how to carry out techniques. They all considered their role as teachers as being about developing people: who loved learning and could function in and contribute to their environments socially. This was perhaps surprising since their education system focused heavily on memorisation for exams.

How participants' perceptions changed regarding collaborative interaction

Without exception, these Senior Teachers came to appreciate in a transformative way, how much more they could learn from others than they had appreciated. They all started with good intentions, but by the end of the TLT-Intervention, they could clearly see that the potential for their own learning lay partly in the ideas of their more junior colleagues or pupils. Learning started to appear to them to be a two-way process (Brown et al 1993; 
Wells 2000). One important finding was that it was not only the content of what others said which had influence: their enthusiasm or creativity could provoke learning too. When the teacher from a more advantaged school saw how the less advantaged teacher still took on enterprising challenges, this boosted her own drive to learn (Hart, 2000).

Having their own views valued by others also inspired the Senior Teachers' learning (Mercer 2000). It seemed to give them confidence and help them feel that they had some professional authority. This was the case, even when appreciation came from less senior teachers. That was a transformational insight within the Egyptian system where only praise from those with senior authority roles tended to be valued (Hammad 2010). But when working as a team, as one member's activities were clearly successful, all members of the team felt driven to learn more. Unlike models of 'success' in the existing system, as the TLT supported each other, the group of teachers abandoned personal gratification in favour of mutual benefit (Rogers 1951, 283).

Another way that the case-study teachers described learning was by being demonstrated to or having a practice exemplified in real life. At the start of the TLT-Intervention, some of the Senior Teachers expressed the belief that it was their job to show junior teachers how to carry out tasks correctly. However, they later related that the 'coaching' approach promoted by the TLT-Intervention transformed this early belief. They came to notice how being asked by the consultants to express themselves, and being listened to, supported them to act proactively. Then, by exemplifying coaching behaviour themselves, they themselves learnt more from their colleagues while also supporting their colleagues' learning more. However, in order to make 'reflective interaction to flow freely without trying to impose her/his own values or wishes' (Shayer 2003,481), time and space needed 
to be made systemically available for such coaching conversations. These commodities were in short supply in all the case-study schools, a lack that seemed to obstruct all teachers' learning.

Participants' perceptions of self-direction as a trigger for learning and a means for achieving their own goals

One strong message that came through our interviews was the enjoyment experienced by the participants during the TLT-Intervention meetings and activities, which enhanced their curiosity, innovativeness and creativity. As Vygotsky emphasised, volition and interest led their developmental process. In fact, it was this spark, this 'spirit' as Laila called it, that set learning into motion. It was this energy that led the participants to try to overcome the gap between their current and their desired capabilities. Participants all commented on how they had previously slipped into boring routines which the Intervention had shaken up. They all remarked that this flame was born out of their own volition, not as a result of rewards, punishments or threats (Niemiec and Ryan 2009). They had come to see why these latter motivators did not entice them to engage in the big and sometimes difficult process of learning. A good explanation lay in their experiences of the classroom observations made by their peers, in which they had chosen their own observers, whose views they had specifically requested. Because they themselves initiated these observations, they felt encouraged to make them useful and make changes based on the observer's comments. This was in stark contrast to the judgemental observations by supervisors that they were accustomed to.

This exercise of their own agency seemed to transform participants' sense of professional self and their confidence. As they directed their own actions and observed the changes they 
inspired, they seemed to feel more authoritative as professionals. Their professional identities transformed as they became entrepreneurs who drove their own learning agenda. This was perhaps the area in which transformation was most evident: participants seemed to move, in Paulo Freire's famous words, from spectators to actors, from followers of prescriptions to makers of choices, from silent participants to outspoken collaborators $(1972,25)$.

Participants noted that an important ingredient in this shift was the setting of a specific, clearly explained, shared goal in the presence of their colleagues who would provide ongoing support. It appeared that the setting of their owned and clearly identified goal, helped them to feel that they were progressing towards a new level of conceptualisation in relation to their professional practice. They came to notice the formation of new functions or the enrichment of existing functions, in relation to this goal, with the support of their Team. Prior to their experience in the TLT-Intervention, their work had seemed less purposeful. They had carried out routines but did not always know what they were working towards or why.

Once purpose was established, with collaborative support systems in place, the participants sought diverse opportunities for developing towards their goal. This drive to find every possible opportunity was especially clear in Saif's case. Rather than waiting for things to be done for them and to them, now the Senior Teachers sought ways to make things happen themselves. This may seem obvious to those of us who enjoy some autonomy in our work, but to the teachers in this study, it was largely a novel idea that learning had to start where the learner started and be subjected to the will of the learner. 
However, we questioned whether we had fostered a new hierarchy among the participants. The Senior Teachers reported that the consultants' guidance bestowed value and status onto all the TLT-Intervention activities. This in turn seems to have led some Senior Teachers' development to have become inextricably linked to the consultants' approval, a dependence which might be assumed to limit their capacity for self-direction. Yet, from a Vygotskian perspective, given the restrictive context within which these Senior Teachers worked, perhaps they were doing exactly what Vygotsky depicted: they were working with the demands and possibilities of the environment and making best use of these. They had found someone to interact with, who could provide a way to move beyond their experience of low status and low authority as teachers. And in the Egyptian case, status was easily bestowed through contact with 'native' English speakers. This would explain Saif's constant emphasis on having contact with native English speakers and the fact that all the teachers found it very encouraging when we, as TLT-Intervention consultants, physically visited their teachers at school. Perhaps this should be seen as a clear manifestation of proactive selfdirection itself, rather than dependence. An unquestioning acceptance of 'decisions from above' was a long-established cultural behaviour; by associating strongly with the Intervention consultants, the participants were perhaps using this culturally embedded custom to achieve their own, self-directed goals, even when these appeared different from the TLT-Intervention's goals.

It is against the backdrop of these deeply embedded hierarchical customs that the academic significance of this article needs to be considered. This research took place in the context of a middle-income country, where typically collaboration could be considered threatening within inflexible hierarchies of power; and conformity was emphasised to the exclusion of development (Hammad 2010). As in other recently independent nations, in Egypt there has 
seemed to linger 'a deeply entrenched culture of obedience and conformity... that compels the rights and privileges of the larger society over the individual' (Ab Kadir 2017, 237). None the less, the research vividly illustrates that personally fulfilling and developmental learning still occurred when the individuals within these constraints engaged in collaborative interaction with others in their environment; and when they directed their own ways forward. Although Vygotsky's views are Eurocentric and therefore not universally applicable, our research seemed to confound this exclusionary assumption. Despite hostile cultural tradition, despite obstructive locally-reinforced habits, when given the opportunities flagged up by Vygotsky, professional learning and development flourished, with the support of a More Knowlegable Other and a Team of colleagues.

\section{Acknowledgements}

Many thanks are due to the Senior Teachers who allowed us to research their practice over the course of the Intervention. Thanks are also due to Prof. Alex Moore and Dr. John Hardcastle for their very helpful comments on an earlier version of this paper.

\section{REFERENCES}

Ab Kadir, M. 2017. "Engendering a Culture of Thinking in a Culture of Performativity: The Challenge of Mediating Tensions in the Singaporean Educational System." Cambridge Journal of Education 47 (2): 227-246.

Bellibas, S., O. Mehmet, and S. Gedik. 2017. "Investigating Professional Learning Communities in Turkish Schools: The Effects of Contextual Factors.' Professional Development in Education 43 (3): 353-374.

BSA, British Sociological Association. 2002. Statement of Ethical Practice. http://www.britsoc.co.uk/media/27107/StatementofEthicalPractice.pdf 
Brown, A.L., and D. Ash, M. Rutherford, K. Nakagawa, A. Gordon and J. Campione. 1993.

'Distributed Expertise in the Classroom'. In Distributed Cognitions: Psychological and

Educational Considerations, edited by G. Salomon, ed., 188-228. Cambridge: CUP.

Carnell, E., J. MacDonald and S. Askew. 2006. Coaching and Mentoring in Higher Education:

A Learning-centred Approach. London: Institute of Education.

Chaiklin, S. 2003. "The Zone of Proximal Development in Vygotsky's Analysis of Learning and Instruction.'" Vygotsky's Educational Theory in Cultural Context 1: 39-64.

Earley, P., and V. Porritt. 2010. Effective Practices in Continuing Professional Development:

Lessons from Schools. London: Institute of Education.

Fielding, M. 1996. 'Beyond Collaborative interaction: On the Importance of Community.' In Consorting and Collaborating in the Education Market Place, edited by D. Bridges and C. Husbands, 149-167. London: Falmer.

Freire, P. 1972. "Pedagogy of the Oppressed. 1968." Trans. Myra Bergman Ramos. New York: Herder.

Glaser, B. and A. Strauss. 1967. "Grounded Theory: The Discovery of Grounded Theory. Sociology: The Journal of the British Sociological Association, 12, 27-49.

Lincoln, Y. and E. Guba. 1985. Naturalistic inquiry (Vol. 75). London: Sage.

Hammad, W. 2010. “Teachers' Perceptions of School Culture as a Barrier to Shared Decisionmaking (SDM) in Egypt's Secondary Schools". Compare 40 (1): 97-110.

Hammad, W. 2016. Conflicting Road Maps: Cross-cultural Professional Development for Egyptian Educators. Compare: A Journal of Comparative and International Education 46 (2):

293-313. 
Hargreaves, E., M. Mahgoub and D. ElHawary. 2016. An Investigation into Improved Primary School English Language Learning in the Crowded Classroom: Pupils Explain what Teachers and Children Can Do to Make Progress (An Egyptian Case Study). Cairo: British Council.

Hargreaves, E. and D. ElHawary. 2018. "Professional Development through Mutually Respectful Relationship: Senior Teachers' Learning against the Backdrop of Hierarchical Relationships". Professional Development in Education.

Hart, S. 2004. Learning without Limits. UK: McGraw-Hill Education.

King, F. 2014. "Evaluating the Impact of Teacher Professional Development: An Evidencebased Framework." Professional Development in Education 40 (1): 89-111.

Leahy, S., and D. Wiliam. 2011. "From Teachers to Schools: Scaling up Professional Development for Formative Assessment". In Assessment and Learning, edited by John Gardner. 2nd ed, 49-71. Thousand Oaks, CA: Sage.

Maxwell, J. 2012. Qualitative Research Design: An Interactive Approach. London: Sage.

Mercer, N. 2000. Words and Minds. Oxford: Routledge.

Mezirow, J. 1990. How Critical Reflection Triggers Transformative Learning: A Guide to Transformative and Emancipatory Learning. San Francisco: Jossey Bass.

Niemiec, C., and R. Ryan. 2009. "Autonomy, Competence, and Relatedness in the Classroom: Applying Self-determination Theory to Educational Practice". School Field, 7 (2): 133-144.

Philpott, C., and C. Oates. 2017. "Teacher Agency and Professional Learning Communities; What Can Learning Rounds in Scotland Teach Us?." Professional Development in Education 43 (3): 318-333. 
Pratt, N. 2007. Democracy and Authoritarianism in the Arab World. Boulder, CO: Lynne Rienner Publishers.

Rogers, C. 1951. Client-centered Therapy: Its Current Practice, Implications, and Theory. London: Constable.

Shayer, M. 2003. “Not Just Piaget; Not Just Vygotsky, and Certainly not Vygotsky as Alternative to Piaget.'" Learning and Instruction 13 (5): 465-485.

Stoll, L., R. Bolam, A. McMahon, M. Wallace, and S. Thomas. 2006. “Professional Learning Communities: A Review of the Literature." Journal of Educational Change 7:221-258.

Tannehill, D., and A. MacPhail. 2017. "Teacher Empowerment through Engagement in a Learning Community in Ireland: Working across Disadvantaged Schools." Professional Development in Education 43 (3): 334-352.

Van der Veer, R., and Valsiner, J. 1991. Understanding Vygotsky: A Quest for Synthesis. Oxford: Blackwell.

Vygotsky, L. S. 1978. Mind in Society. London: Harvard University Press.

Vygotsky, L. S. 1962. Thought and Language (E. Hanfmann \& G. Vakar, Eds. And Trans.). Cambridge, MA: MIT Press.

Wells, G. 2000. 'Dialogic Inquiry in Education: Building on the Legacy of Vygotsky'. In Vygotskian Perspectives on Literacy Research, edited by C.D. Lee, 51-85. Cambridge: Cambridge University Press.

Yandell, J. 2007. “Investigating Literacy Practices within the Secondary English Classroom, or Where is the Text in this Class?." Cambridge Journal of Education 37 (2): 249-262. 